\title{
O MODO DE VIDA RIBEIRINHO NA ILHA DO JANUÁRIO NO RIO AMAZONAS
}

\author{
THE RIVERINE PEOPLE LIVING MODE ON JANUARY \\ ISLAND IN THE AMAZON RIVER
}

\author{
EL MODO DE VIDA RIBEREÑO EN LA ISLA DE \\ JANÚARIO EN EL RÍO AMAZONAS
}
Camila de Oliveira Louzada - Universidade Federal do Ceará - Fortaleza - Ceará - Brasil camila.louzada.88@gmail.com
Jesuéte Pachêco Brandão - Universidade Federal do Amazonas - Manaus - Amazonas - Brasil geogensino@gmail.com
Elizabeth da Conceição Santos - Universidade do Estado do Amazonas - Manaus - Amazonas - Brasil draelizabethsantos@gmail.com

\section{Resumo}

A análise desenvolvida neste estudo versa sobre o modo de vida das populações tradicionais do estado do Amazonas, denominados ribeirinhos, e o tipo de sistema produtivo que empregam na faixa justafluvial do Rio Amazonas, onde residem. A área de estudo é a comunidade rural Nossa Senhora da Conceição, situada na llha do Januário, localizada no município de Itacoatiara, a $270 \mathrm{~km}$ da cidade de Manaus. A metodologia utilizada está baseada na revisão bibliográfica, em visitas de campo e em registros fotográficos. 0 s resultados encontrados foram: i) a base da economia ribeirinha da Ilha do Januário é a agricultura familiar; ii) a produção é diversificada, e o excedente é direcionado ao abastecimento da cidade de Manaus; iii) falta de políticas públicas voltadas para a agricultura familiar dos ribeirinhos, no estado do Amazonas. Devido a isso ou apesar disso, os ribeirinhos continuam a residir nesse lugar e a reproduzir seu modo de vida, produzindo policulturas com mão de obra familiar e abastecendo o mercado consumidor da cidade de Manaus há gerações.

Palavras-chave: Ribeirinhos do Januário, agricultura familiar, políticas públicas.

\section{Abstract}

Analysis developed in this study deals with the Amazonas state "traditional" populations way of life, denominated riverine people, and the type of productive system used in riparian zone of the Amazon river where they live. The study area is the rural community of Nossa Senhora da Conceição, located on Januário Island, in the Itacoatiara municipality, $270 \mathrm{~km}$ from the city of Manaus (Brazil). Methodology used in the present research is a bibliographical review, the fieldwork, and the photographic records. The results were: i) the Januário Island riverine economy base is the family agriculture; ii) the production is diversified, and the surplus is directed to the supply the city of Manaus; iii) lack of public policies regarding the riverine people family agriculture, within Amazonas State. Due to this or despite this, the riverine residents continue to reside at these places, and a reproduction of their way of life, producing polycultures with family labor, and supplying the consumer market of the city of Manaus generations ago.

Keywords: Januário riverines, family agriculture, public policies. 


\section{Resumen}

El análisis desarrollado en este estudio versa sobre el modo de vida de las poblaciones tradicionales del estado de Amazonas, denominadas ribereños, y el tipo de sistema productivo que emplean en la zona ribereña del río Amazonas donde viven. El área de estudio es la comunidad rural Nossa Senhora da Conceição, ubicada en la Isla de Januário, en Itacoatiara/AM, cerca de $270 \mathrm{~km}$ de la ciudad de Manaos (Brasil). La metodología utilizada en la presente investigación está basada en la revisión bibliográfica, en visitas de campo y en registros fotográficos. Los resultados encontrados fueron: i) la base de la economía de los ribereños de la Isla del Januário es la agricultura familiar; ii) la producción es diversificada, y el excedente es direccionado al abastecimiento de la ciudad de Manaos; iii) la falta de las políticas públicas relacionadas a la agricultura familiar de los ribereños, en el estado de Amazonas. Debido a eso o a pesar de ello, los ribereños continúan residiendo en este lugar, y reproduciendo su modo de vida, produciendo policulturas con mano de obra familiar, y abasteciendo el mercado consumidor de la ciudad de Manaos desde hace generaciones.

Palabras clave: Ribereños del Januário, agricultura familiar, políticas públicas.

Introdução

Estudos pioneiros dão conta da presença de grande número de populações vivendo e produzindo alimentos em quantidade suficiente para a sobrevivência das populações tradicionais (Meggers, 1977; Denevan, 1976; Lathrap, 1975) ao longo das calhas dos Rios Solimões, Madeira e Amazonas. Sobre isso Roosevelt et at. (1996) afirmaram que os vestígios de ocupação humana na Amazônia foram localizados nas proximidades da cidade de Santarém no Pará e foram datados em 11200 AP (Roosevelt et al. 1996, p. 374). As gerações humanas posteriores a esse registro continuaram a residir na Amazônia, onde seus descendentes vivem até hoje, mantendo seu modo de vida particular, e são conhecidos atualmente como populações locais ou tradicionais, tendo uma relação direta com as águas que banham as extensas planícies da Bacia Amazônica.

Como populações locais ou tradicionais, entende-se aquelas que geracionalmente usam de suas estratégias culturais, no uso e na ocupação da terra de um determinado lugar ou território. Para Louzada (2014, p.52), essas populações tradicionais são aquelas etnicamente diferentes das sociedades nacionais dominantes dos países onde vivem, haja vista a forte relação diferenciada com o sistema natural à sua volta.

Para Vianna (2008, p.209), as populações tradicionais formam um conjunto de pessoas residentes em um lugar, detentoras de uma relação direta com a natureza, por meio do uso dos recursos naturais, de atividades extrativistas e/ou agricultura com tecnologia de baixo impacto no sistema ambiental. Destacam-se nessa categoria: pescadores artesanais, pequenos agricultores, caiçaras, caipiras, camponeses, extrativistas, pantaneiros 
e ribeirinhos. Essas populações tradicionais, devido ao contato direto com o ecossistema, são portadoras de características positivas para a sua conservação. Por exemplo: a adaptação às sazonalidades ambientais; o etnoconhecimento de manejo sustentável dos sistemas naturais, e a condição de produtores de biodiversidade.

Para Louzada (2014, p.52), na Amazônia brasileira, as populações locais e/ou tradicionais recebem vários nomes, de acordo com o lugar de onde pertencem:

a) no estado do Pará - i) as populações ligadas à economia de extração de produtos naturais recebem os nomes de extratores ou extrativistas; ii) os habitantes da Ilha do Marajó são denominados de marajoaras ou marajás; iii) em Óbidos, há os varzeiros e os terrafirmeiros;

b) no estado do Amazonas - i) Pacheco et al. (2012 e 2014) e Sternberg (1998) intitulam de varzeanos os moradores das várzeas do município de Careiro da Várzea; ii) Pacheco (2013) e Brandão (2016) denominam as famílias tradicionais da Gleba Vila Amazônia como assentados e/ou parceleiros da Agricultura Familiar; iii) segundo Louzada (2014, p. 54), no Amazonas, as populações tradicionais recebem o nome de ribeirinhos, pois, além de se localizarem muitas vezes distantes de centros urbanos, estão assentadas nas áreas de várzea ao longo dos rios de água branca. Apesar das diferentes nomenclaturas, todas convergem para abordar a relação entre homem e natureza, o espaço no ecossistema de várzea e as transformações na paisagem decorrentes dessa interação.

Sorre (1967) estudou a relação entre homem e meio ambiente, através da sua organização espacial e das técnicas empregadas. Para ele, o espaço seria o resultado da coabitação do homem e da natureza, cercado por intencionalidade (Braga, 2007, p. 67). Nesse sentido, Santos (1988, p. 88) afirma que a reorganização do espaço e as diversas formas de relacionamento com o meio exigem uma relação de aprendizagem e vivência.

Já para Rego (2007, p. 43), o espaço geográfico é um produto histórico e deve ser entendido como um conjunto indissociável de sistemas de objetos e de ações, que mostra as práticas sociais dos diferentes grupos que nele interagem, produzem, sonham, lutam, desejam, vivem e (re)constroem.

Todas as ações humanas sobre o espaço geográfico refletem na paisagem. Nesse sentido, Santos (2006, p. 66) afirma que a paisagem exprime as heranças que representam as sucessivas relações entre o homem e a natureza. 
Diante do exposto, a Ilha do Januário faz parte do município de Itacoatiara (Mapa 1), localizado a $200 \mathrm{~km}$, por via fluvial, da cidade de Manaus. Atualmente, residem na localidade 100 famílias ribeirinhas distribuídas em pequenas propriedades, baseando sua renda na agricultura familiar, ou em fazendas de gado, com áreas variando entre 10 e 500 hectares. Cabe ressaltar que as moradias não estão aglomeradas em núcleos comunitários ou em vilas comuns em outros municípios do estado.

A proposta deste estudo é contribuir para a discussão sobre a relação entre o homem e o meio ambiente amazônico, no ecossistema de várzea, e sua adaptação ao regime das águas, para a produção da agricultura familiar, além de seu modo de vida.

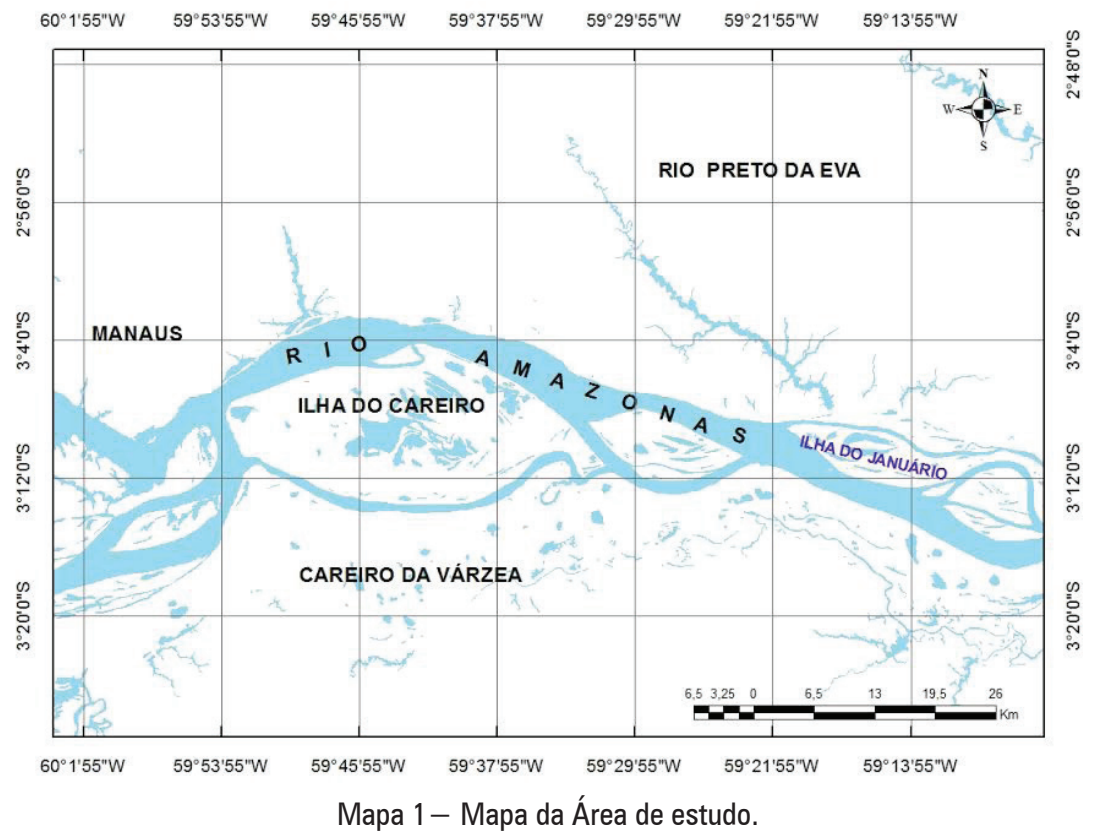

Fonte: Jesuéte Brandão (2017).

A Comunidade Rural Nossa Senhora da Conceição, situada na Ilha do Januário, tem aproximadamente $10 \mathrm{~km}$ de extensão, sem contar o arquipélago de ilhas posterior à comunidade. A ilha é constituída de material de formação sedimentar do Quaternário recente (Pinto, 2016), período Holoceno (aproximadamente $10 \mathrm{mil}$ anos). 
Este artigo é motivado por duas perguntas relevantes: de qual Amazônia estamos falando? Quais as características dos ribeirinhos da Ilha do Januário e qual é sua relação com o meio à sua volta? Tem-se como base o livro Amazônia, Amazônias, de Carlos Walter Porto Gonçalves, que propõe olharmos a região além de sua paisagem amplamente generalizada ao longo dos séculos, dando visibilidade às suas particularidades locais e regionais.

Para Gonçalves (2005), a definição de Amazônia "é, na verdade, mais uma imagem sobre a região do que da região" (Gonçalves, 2005, p. 17). Em outras palavras, a descrição das características físicas da região define um quadro mais ou menos homogêneo sobre a região, quando, na verdade, o termo Amazônia

[...] é um termo vago, que adquire múltiplos significados correspondente aos mais diferentes contextos socioecológico-culturais específicos que são os espaços do seu cotidiano. Assim, enquanto para uns - os de fora, "Amazônia" aparece no singular, para outros, isto é, para os que nela moram - ela é plural e multifacetada (Gonçalves, 2005, p.18).

Nesse sentido, existem várias Amazônias, dentro da Amazônia amplamente divulgada. Essas Amazônias são compostas pelas populações tradicionais que recebem vários nomes - índios, caboclos, ribeirinhos, seringueiros ou quilombolas. Todas apresentam vasto conhecimento sobre a fauna e a flora do ecossistema ao qual estão inseridas, assim como das técnicas de utilização dos recursos da natureza, para sua sobrevivência e a reprodução de seu modo de vida.

Nesse sentido, Posey (1980) afirma que "os povos tradicionais percebem a 'natureza' não como somente um inventário de recursos naturais disponíveis, mas representante das forças espirituais e cósmicas que fazem da vida o que ela é” (Posey, 1980, p. 149-150).

Modo de vida ribeirinho e suas inter-relações com a natureza

Para Silva et al. (2002, p.2), a população ribeirinha mantém um modo de vida característico que a distingue das outras populações (urbana e a rural do centro e/ou topos dos interflúvios), devido a sua proximidade com o rio. Para essas unidades familiares, o rio não é apenas um elemento do cenário ou da paisagem visível e estática. 
Sobre isso, Cabral (2002, p.2) relata que o ribeirinho integra o grupo das populações tradicionais, que se percebe pertencente à natureza, em seu tempo-espaço próprio, fluindo com ela nas suas diversas funções e não a dominando.

Para Oliveira (2002), as populações ribeirinhas são resultado de fracassadas tentativas de ocupar a Amazônia brasileira, seja com mão de obra nordestina no final do século XIX para a retirada do látex da hevea brasiliensis, seja durante a Segunda Guerra Mundial (até meados da década de 1940), com os soldados da borracha (nordestinos e de outras nacionalidades). Passados esses momentos de atividade e sem o apoio do poder público, gradativamente foram abandonando os seringais e, deixadas à própria sorte, foram criando estratégias para viver na Floresta Amazônica.

Para Cabral (2002, p.2), os ribeirinhos:

[...] ora são tratados como vítimas de uma sociedade excludente, ora como índios, preguiçosos, como heróis das selvas por conseguirem adaptar-se a uma floresta e raras vezes como pessoas que definiram uma filosofia de vida, o fato é que, em geral, o ribeirinho é marginalizado (Cabral, 2002, p.2).

Corroborando os registros do estudo em pauta, Diegues (2001) destaca que as comunidades ribeirinhas estão diretamente ligadas aos rios, igarapés, lagos, constituidores do complexo ecossistema amazônico.

Para Louzada (2014, p. 53), as diversas definições de ribeirinho servem para destacar um ponto em comum: o elo de proximidade com os rios, igarapés, paranás, furos. Esses elementos da natureza hídrica têm uma importância vital, pois são o principal meio de locomoção em grande parte da Floresta Amazônica. Todavia, esse elo é superior à necessidade de locomoção, já que esses corpos d'água também são fontes do alimento básico dessas populações, o peixe.

Outro ponto de destaque diz respeito ao modo de vida do ribeirinho, diferente dos agricultores familiares (assentados, parceleiros, castanheiros etc.), que geralmente residem em pequenos núcleos exclusivamente em áreas de terra firme da Amazônia, não tão próximos a qualquer curso d’água. A principal característica dos ribeirinhos da Amazônia é sua localização em áreas de várzea exclusivamente às margens dos rios de água branca, tendo sua economia solidamente baseada na agricultura familiar de policulturas. 
As comunidades geralmente são compostas por entre 20 e 40 casas, construídas de acordo com o lugar e a necessidade: tipo palafita (Foto 1), para ficar fora da ação das águas no período de cheia dos rios da Amazônia, ou casas-flutuantes (Foto 2).

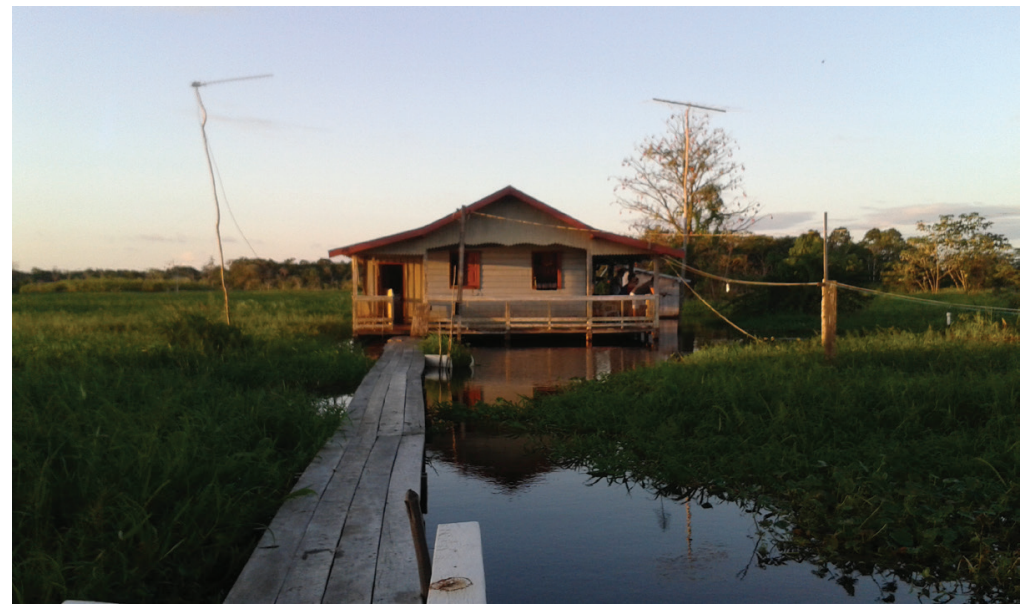

Foto 1 - Casa ribeirinha, construída para ficar fora da ação das águas do Rio Solimões/Amazonas

Fonte: Camila Louzada (2015).

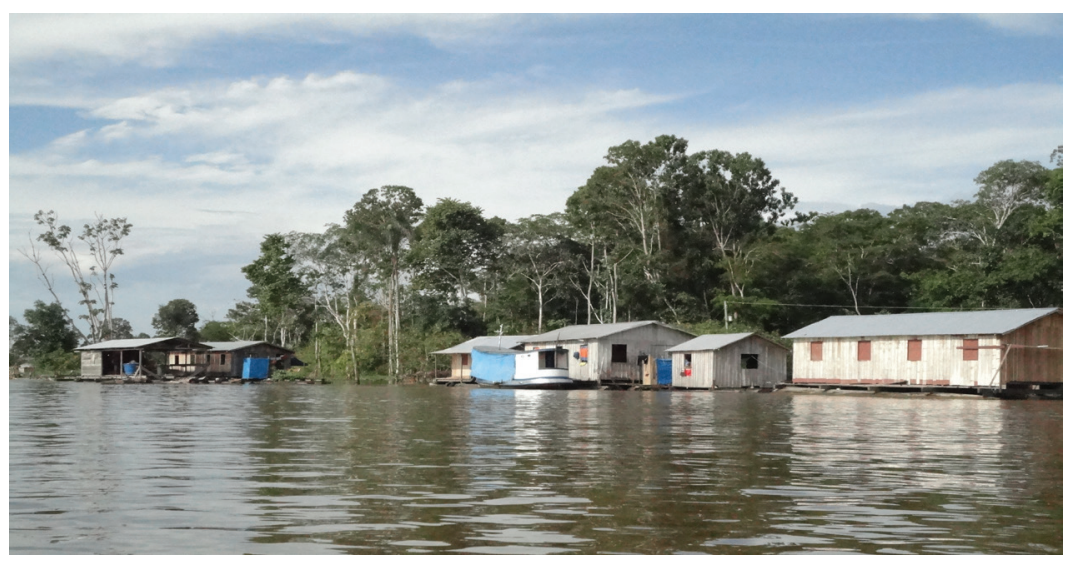

Foto 2 - Casas flutuantes localizada no Rio Solimões/Amazonas 
Cabe ressaltar o quanto a proximidade do ribeirinho com a hidrografia é maior do que a necessidade de locomoção e fornecimento de alimento, pois existe uma ligação afetiva com o lugar que ocupa. Sobre isso, Tuan (2012) destaca que o elo afetivo entre um conjunto de pessoas e o lugar é definido como topofilia. A relação homem e meio ambiente é baseada na experiência pessoal de cada indivíduo com o meio à sua volta, fundamentada por atitudes e valores construídos ao longo do tempo. Ex: adultos, que um dia quando crianças brincaram em um lugar arborizado, subiram em árvores para comer frutos direto da árvore, têm uma relação diferente com a natureza, no geral nostálgicas e respeitosas tanto com a natureza mais também com outras pessoas, o que é um posicionamento diferente da maioria dos adolescentes hoje, que nasceram na geração da internet e nunca souberam o que era brincar na rua, subir em uma árvore, pois a maioria foi criada e permanece reclusa dentro de casa. Sua postura diante da natureza e da sociedade tende a ser fria e indiferente, o que os tornará adultos egocêntricos.

\section{0 rio comanda a vida no anfiteatro amazônico}

Leandro Tocantins (1964) aborda a importância do regime das águas sobre o modo de vida dos povos da Floresta Amazônica. Para ele, a região é entalhada por uma complexa rede hidrográfica, cujo rio principal é o Amazonas, caracterizado por uma variação sazonal que depende dos altos índices pluviométricos anuais. Esse suporte favorece a diversidade de fauna, da flora e de múltiplas culturas, tornando a Região Amazônica um palco de espetáculos belíssimos em sua paisagem (Foto 3). 


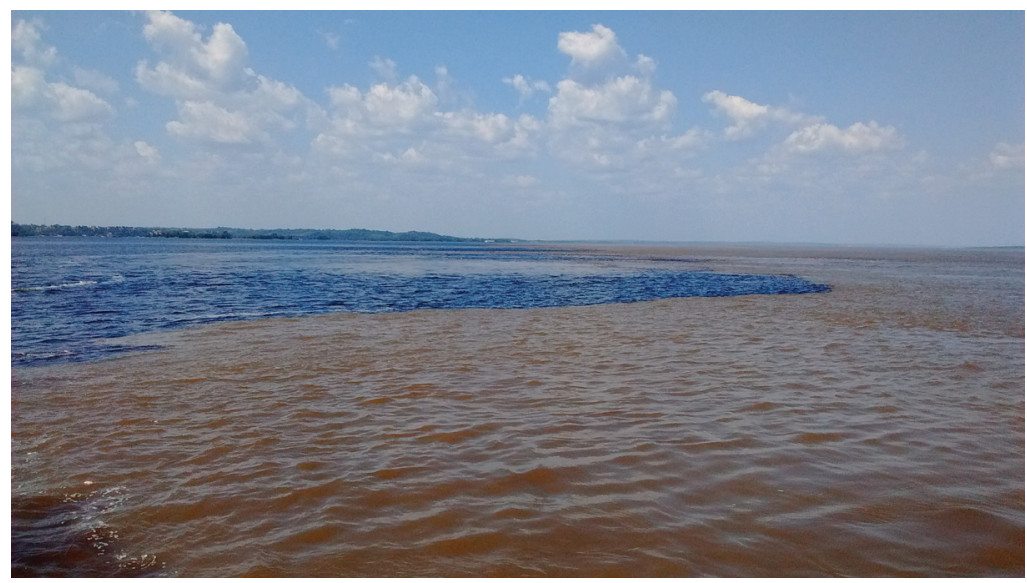

Foto 3 - Encontro das águas dos Rios Negro e Amazonas/Solimões

Fonte: Camila Louzada (2015).

Sioli (1984) afirma que as águas de cor branca são decorrentes da fertilidade trazida na carga dendrítica depositada anualmente sobre as várzeas. Louzada (2014), atendo-se ao aporte de Guerra (1993), descreve que a Amazônia está dividida em dois ambientes completamente distintos: o ecossistema de terra firme e o ecossistema de várzea.

$\mathrm{O}$ ambiente de terra firme representa um complexo ecossistema que está fora da ação das águas pelos regimes dos rios e pelas marés, ou seja, os processos sazonais de enchentes anuais e marés diárias não ultrapassam a borda do leito maior das faixas justafluviais. Ao contrário desse ecossistema, a várzea é constituída de terrenos com altimetria baixa, que permite o transbordamento de enchentes sazonais anuais, dependendo da cota (Louzada, 2014, p.54).

Essas variações de altimetria da planície amazônica, somadas ao regime fluvial dos rios que banham a região, influenciam diretamente os tipos de solos encontrados em cada ecossistema, o que acaba por determinar que tipo de cultivo é ideal para cada ambiente.

Ao contrário do que se divulga a Amazônia não dispõe somente de solos 'pobres', sustentados por sua floresta, mas também de solos ricos por natureza, como é o caso dos solos de várzea, com alta concentração de depósitos aluviais, utilizados para os cultivos agrícolas de ciclo curto, de frutas e verduras, que abastecem as 
cidades mais próximas, incluindo a capital do estado do Amazonas, Manaus (Louzada, 2014, p.54).

A fase de vazante dos rios é considerada um período de fartura e até mesmo de superabundância de produtos agrícolas, além dos peixes disponíveis nos rios, lagos e nas restingas das várzeas. Já no período de cheia, a produção agrícola é praticamente zerada, uma vez que as áreas agrícolas estão submersas e os peixes se refugiam em áreas protegidas para o período de reprodução.

A deposição anual de nutrientes nas várzeas da Amazônia torna os solos férteis, permitindo às comunidades ribeirinhas produzirem seus alimentos nas áreas de várzea em seu período seco (entre agosto e fevereiro, geralmente). A produção agrícola familiar ribeirinha baseia-se no plantio de cultivos de ciclo curto (hortaliças - pimentão, cebolinha, coentro, alface, couve, berinjela, pepino, pimentas etc.; e frutas - melancia, maracujá, banana, melão e outras) (Foto 4).

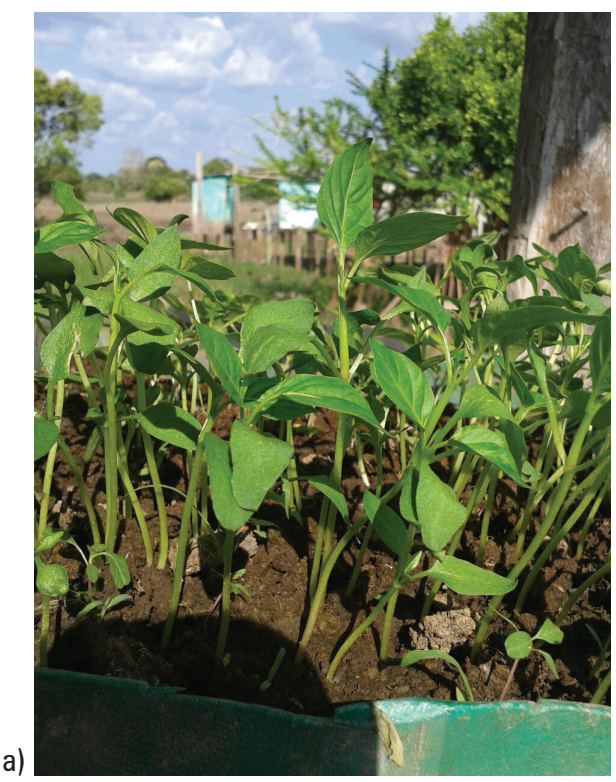




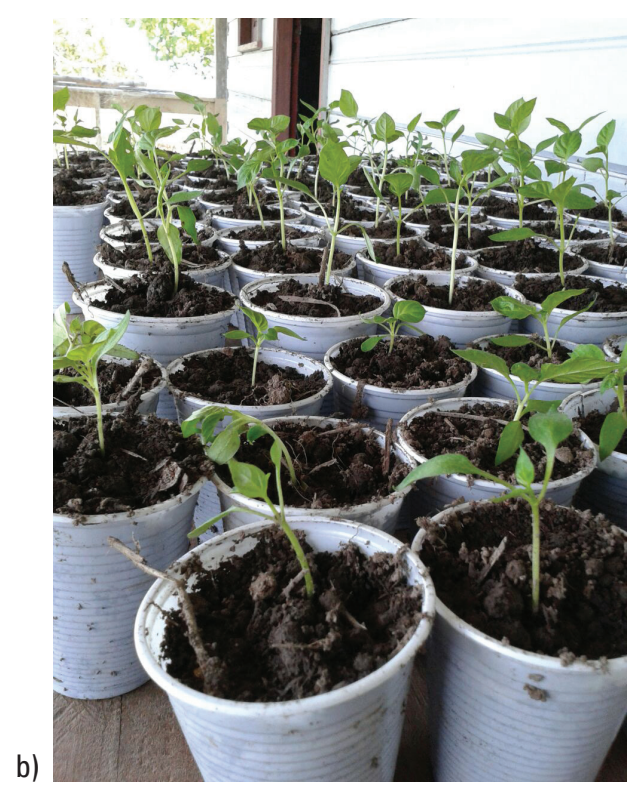

Foto 4 - a) Mudas de pimentão/ b) Mudas de melancia

Fonte: Rosalia Louzada (2015).

Os cultivos agrícolas de ciclo curto são a opção unânime dos ribeirinhos, uma vez que o tempo exigido entre plantio e colheita é o mais bem adequado para a produção no período em que a várzea passará enxuta. Exemplo: a produção de melancia e maracujá, em que as sementes são cultivadas primeiramente em copos plásticos, entre os meses de julho e agosto, e posteriormente as mudas são plantadas diretamente no solo de várzea, nos meses de agosto e setembro. Os frutos de melancia estarão prontos para começar a ser colhidos entre os meses de outubro e novembro e os de maracujá, a partir de novembro, A produção continuará até que a subida das águas do ano seguinte mate as plantas (Foto 5). 


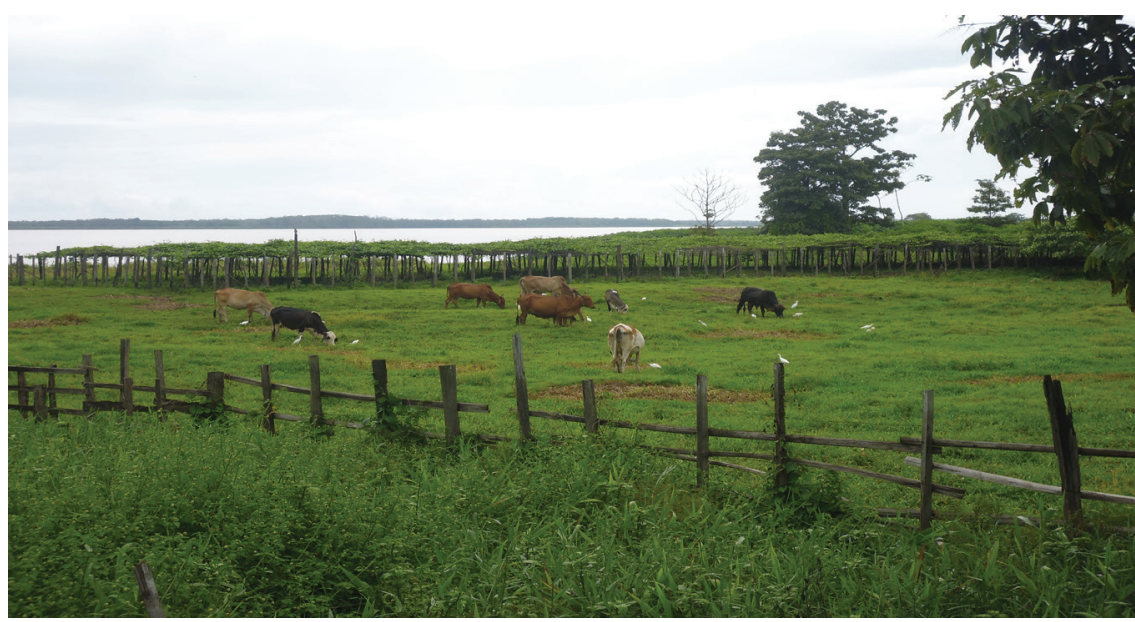

Foto 5 - Plantação de maracujá

Fonte: Camila Louzada (2016).

Durante o período de cheia dos rios, os ribeirinhos têm duas escolhas: ou permanecem em suas casas sobre as águas - mantendo seus animais em abrigos temporários, descritos por Sternberg (1998) como marombas (pequeno curral suspenso por madeiras flutuantes), e alimentando-os com capim aquático -, ou migram para as áreas de terra firme, até que o período de vazante dos rios se inicie.

Outra estratégia muito utilizada pelos ribeirinhos para abrigar seus animais é a maromba erguida. Nesse caso, retira-se solo de um determinado local para aterrar outro, até formar um tabuleiro de dimensões e altura variáveis, conforme os interesses do ribeirinho (Foto 6). Geralmente, esse processo ocorre na parte mais elevada do terreno. Todo trabalho é realizado de forma manual, pois não é comum encontrar maquinário agrícola nas várzeas da Amazônia. 


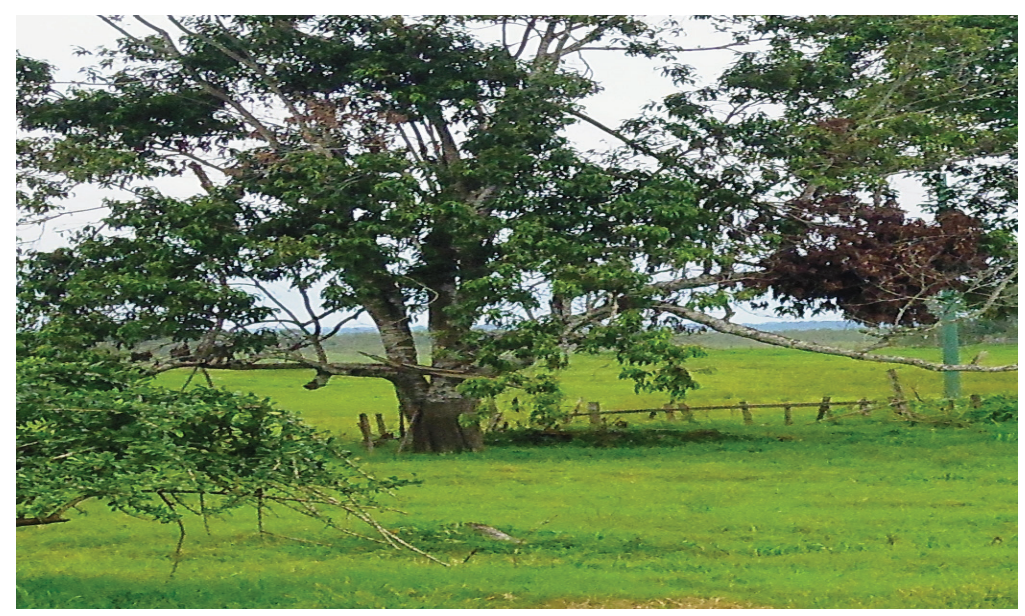

Foto 6 - Maromba construída de formal manual, sob a sombra de uma árvore

Fonte: Camila Louzada (2017).

Nessas marombas em formato de tabuleiro, o gado pode passar todo o período de cheia dos rios, sendo alimentado por capim aquático muitas vezes transportado por longas distâncias em pequenas embarcações (Foto 7). Ou pode ser transferido para a terra firme até o período de vazante se iniciar, geralmente no mês de julho.

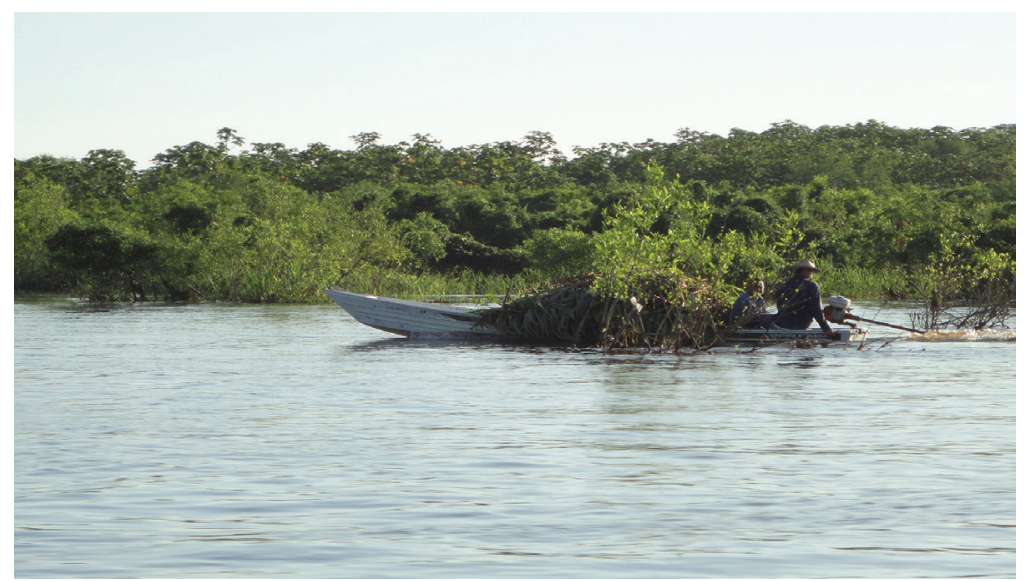

Foto 7 - Ribeirinho transportando capim para o gado comer na terra firme 
Os ribeirinhos de situação econômica mais estável costumam residir durante todo o período de cheia fluvial nas áreas de terra firme. Para isto ocorrer, eles avaliam se as suas propriedades não estão afetadas por pragas agrícolas comuns nestas áreas, que atacam a base alimentar da maioria dos animais transportados, como as formigas cortadeiras (Atta cephalotes), as cigarrinhas-de-pastagem (Homoptera-Cercopidae) e a espuma de capim (Zulia entreriana).

As várzeas tornam-se perigosas em seu período de cheia não só para os animais, mas também para os próprios ribeirinhos, devido às grandes áreas submersas, uma vez que o território dos jacarés, de forma geral, e principalmente do jacaré-açu (Melanosuchus Níger), é expandido para a busca de alimentos, os quais ficam praticamente escassos nesse período. Assim, tornam-se comuns os casos de ataques desses animais aos ribeirinhos, principalmente crianças, nessa época do ano.

Muito embora haja toda essa complexidade de fatores envolvidos na interação homem- natureza, os ribeirinhos sempre criam novas estratégias para seguir em frente, sem abandonar seus hábitos e costumes. Nesse sentido, Tocantins (1964) descreve a importância dos rios da Amazônia:

Como veias de sangue da planície, caminho natural dos descobridores, [...] a fonte perene do progresso, [...] asseguraram a presença humana, embelezaram a paisagem, fazem girar a civilização comandam a vida no anfiteatro amazônico (Tocantins, 1964, p.64).

Os rios de água branca, ao dinamizar a tríade fluvial (erosão, transporte e deposição), vão emoldurando a paisagem com praias de areia branca em formato longitudinal, geralmente no meio dos canais fluviais. O ribeirinho sabe o momento certo de habitar essas formações aluviais, denominadas de ilhas fluviais. Segundo Pacheco et al. (2012, p.543), o surgimento (depósitos aluviais) ou desaparecimento (erosão fuvial e/ou terras caídas) de uma ilha fluvial decorre da dinâmica fluvial, assim, constantemente é modificada a fisionomia da paisagem visível (casa, sistemas produtivos, vegetação, fauna, solo etc.) e da invísível (cultural geracional).

\section{Produção agrícola e o mercado consumidor}

Os ribeirinhos da comunidade N. S. da Conceição, no processo de comercialização de seus produtos com o centro consumidor de Manaus, 
formam uma cadeia integrada, segundo a definição de Mendes e Padilha Junior (2007), pois não é mais possível separar os vários setores que compõem a produção, a distribuição e a comercialização de alimentos.

Sobre a agricultura ribeirinha praticada na Amazônia, Adams (2005, p. 2) afirma que ela é complexa, não só com nuances ecológicas e regionais, mas também socioculturais. Isso porque cada comunidade ribeirinha tem suas características específicas de produção agrícola, preservando as características gerais, como a utilização prioritária de mão de obra familiar, com o emprego ocasional de mão de obra externa.

A ilha do Januário é definida como um terraço inferior (TINF) (Gonçalves Junior, 2013), caracterizado por apresentar topografia rebaixada com altimetria variando entre 10 e 20 metros (Pinto, 2016). Essa baixa variação altimétrica não é um fator limitador para a produção agrícola.

Os sistemas produtivos são organizados obedecendo aos gradientes de altimetria e à necessidade de cada cultivo (feijão de praia, maracujá, mandioca, melancia, melão regional, jerimum, milho, banana, mamão e verduras como cebolinha, cheiro-verde, pimenta cheirosa, pimentão e couve). No caso da produtividade do milho, ela é destinada prioritariamente à manutenção de criações de galinhas, patos e porcos, em muito pequena quantidade para o abastecimento familiar. Já a produção de feijão de praia é destinada integralmente para o abastecimento familiar.

A mandioca (Manihot esculenta) e os seus derivados estão entre os poucos alimentos produzidos na ilha do Januário que passam pelo processo de agregação de valor. Produz-se a farinha, muito consumida na Amazônia, e, em seu processo, retira-se a goma utilizada para fazer tapioca/beiju e o tucupi (líquido amarelo extraído da raiz da mandioca, venenoso até ser fervido, após isso torna-se comestível), muito utilizado na culinária amazônica, sendo os pratos mais consumidos o pato no tucupi e o tacacá.

Outra atividade econômica praticada na ilha do Januário é a criação de cabeças de gado em pequena escala, geralmente destinada à retirada de leite para a fabricação de queijo coalho, queijo de manteiga, manteiga de gado, além da venda in natura. Em caso de festejo ou de necessidade familiar, para consumo da carne.

De maneira geral, a produção agrícola e seus subprodutos, assim como a pequena criação de animais, destinam-se para o consumo familiar. O excedente segue em transporte fluvial para ser comercializado na cidade de Manaus. 


\section{Políticas públicas para o ribeirinho}

Não existe uma política agrícola específica no estado do Amazonas, implementada para atender o setor primário das famílias ribeirinhas. $\mathrm{O}$ que existe são raras ações do Instituto de Desenvolvimento Agropecuário e Florestal Sustentável do Estado do Amazonas (IDAM), no sentido de fornecer assistência mediante processos educativos, por meio de diálogo com os produtores, cursos de capacitação voltados para o melhoramento da produção, assim como orientações sobre as linhas de créditos disponíveis para o agricultor.

Com apenas esses serviços, o IDAM não supre o atendimento das necessidades exigidas pelo sistema produtivo das famílias ribeirinhas, como: assistência técnica (com propostas adaptadas para o ecossistema de várzea); orientações no sentido de técnicas de armazenagem; meios de transporte e comercialização; controle do uso de pesticidas.

Sobre isso Zambra et al. (2014) afirma que:

[...] os maiores gargalos existentes no setor da agricultura familiar estão ligados aos processos de comercialização e acesso aos mercados, inadequação de embalagens, instalações e tecnologia de produção e, principalmente, no que diz respeito à legislação sanitária e à qualidade destes produtos (Zambra et al. 2007, p.3).

Buainain et al. (2007) complementa que

O fortalecimento da agricultura familiar pode ser alcançado por meio do desenvolvimento do processo de comercialização que possui características peculiares como: seu caráter social; a territorialidade do local onde os produtos são fabricados; o sabor diferenciado originado da característica artesanal do processo produtivo; a justiça social implícita em produtos que aumentam a renda dos pequenos agricultores (Buainain et al, 2007, p. 133).

Como apresentado anteriormente, existe uma variedade significativa de produção oriunda do setor primário da ilha do Januário. Verificaram-se, nos relatos dos ribeirinhos, vários problemas, mas um em específico surgiu em todos os relatos: existe, sim, um grande volume de produção, todavia, poucos produtos são transportados até a cidade de Manaus (o maior mercado consumidor do estado), devido aos custos altíssimos com o transporte fluvial até a capital. 
Desse modo, o escoamento da produção fica comprometido e, quando isso ocorre, não há como complementar a cesta básica com produtos importantes que não são produzidos na comunidade, como açúcar, arroz, café, sal e outros.

Devido à ausência de qualquer política pública voltada aos sistemas produtivos dos ribeirinhos, muitas famílias comercializam seus produtos com o atravessador ou marreteiro, considerado popularmente como um pequeno comerciante que compra a preços muito baixos a produção agrícola para revendê-la em Manaus, principalmente, no Porto da Manaus Moderna, popularmente conhecido como Escadaria dos Remédios (Foto 8).

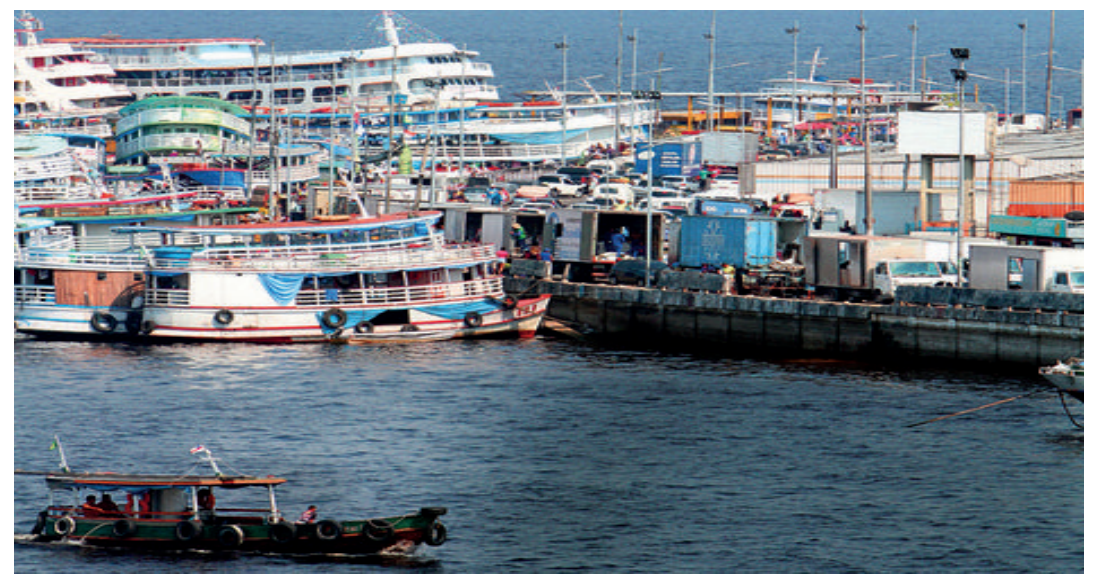

Foto 8 - Porto da Manaus Moderna

Fonte: jornal $A$ Crítica, 2015.

Para Pereira (2016, p.23), "não existe dúvida sobre a invisibilidade social e política dos ribeirinhos, cujo efeito mais perverso, talvez, seja a utilização dessa mesma invisibilidade como recurso para a efetivação das ações dominadoras do Estado”. Ações estas que podem ocorrer de múltiplas formas, sendo a mais propagada a destruição de ecossistemas, grupos culturais e étnicos e modos de vida dos povos que habitam a região, por trás de um discurso legitimamente dominador e hipócrita de "desenvolver a Amazônia", através de grandes obras como a BR-230 Transamazônica, BR-010/Belém-Brasília, BR-319/Manaus-Porto Velho (Louzada, 2014). Mais recentemente, isso ocorre com a construção de 
usinas hidrelétricas em uma área de planície sedimentar, que, na prática, necessita de uma gigantesca área inundada, ao contrário de outras hidrelétricas construídas em áreas de diferentes topografias, como encostas, com altimetrias elevadas.

Essa invisibilidade infligida sobre os ribeirinhos também é demonstrada pela forma como suas reivindicações são ignoradas e desqualificadas pelo poder público, presente no "formidável desprezo pela diversidade e singularidade do modo de vida das populações ribeirinhas" (Pereira, 2016, p.83).

\section{Considerações finais}

No decorrer do artigo, foram respondidas as duas perguntas relevantes apontadas como norteadoras do trabalho: de qual Amazônia estamos falando? Quais as características dos ribeirinhos da Ilha do Januário e qual é sua relação com o meio ambiente à sua volta?

A Amazônia abordada aqui descreve um importante representante da população tradicional da região, o ribeirinho da Amazônia, que se caracteriza por: apresentar uma intrínseca relação com o rio, seu único meio de locomoção e fornecedor do seu alimento primordial, o peixe; ter sua economia baseada na produção agrícola familiar, de policulturas de ciclo curto; utilizar predominantemente mão de obra familiar; residir exclusivamente em áreas de várzeas de rios de água branca do estado do Amazonas.

O ribeirinho residente na comunidade rural Nossa Senhora da Conceição apresenta todas as características gerais descritas acima, e ainda o seu esforço de adaptação do ecossistema de várzea para a criação bovina. Mesmo com suas dificuldades, eles se sentem pertencentes a esse ecossistema, que é a base de seu modo vida, de tão inseridos que estão no meio a sua volta.

Seu modo de vida particular funciona em um emaranhado de redes que se conectam entre o que é natural e o que é artificial, imbricando-se de uma maneira conservacionista e/ou preservacionista e perdurando por meio das estratégias do seu modo de vida, que causa o mínimo possível de impacto.

Portanto, apesar de os ribeirinhos da comunidade rural Nossa Senhora da Conceição serem "agraciados", por parte de seus governantes, 
com a invisibilidade política, por meio da sua prática de agricultura familiar de policulturas, eles continuam a abastecer o mercado consumidor de Manaus há gerações, apesar de todas as dificuldades enfrentadas, baseando-se em seus saberes intrínsecos de aproveitamento do ecossistema que habitam.

Essa capacidade de reprodução de seu modo de vida há gerações, sempre se adaptando às dificuldades do ambiente, faz do ribeirinho uma figura notável pela sua capacidade de resiliência, assim como um verdadeiro amazônida (homem ligado sentimentalmente à região e que faz da Amazônia sua filosofia de vida), que faz de seu modo de vida singular um modelo de interação homem e meio ambiente, no ecossistema de várzea da Amazônia.

\section{Referências}

AMAZONAS (Estado). Lei n ${ }^{\circ} 2.384$, de 18 de março de 1996, que criou o Instituto de Desenvolvimento Agropecuário do Estado do Amazonas (IDAM).

BUAINAIN, Antônio Márcio. Agricultura familiar e a inovação tecnológica no Brasil: características desafios e obstáculos. Campinas: Unicamp, 2007.

BRANDÃO, Jose Carlos Martins. Perdurabilidade da agricultura familiar no Projeto de Assentamento de Vila Amazônia. 2016. Tese (Doutorado) - Programa de Pós-Graduação em Ciências do Ambiente e Sustentabilidade na Amazônia (PPG/ CASA), Centro de Ciências do Ambiente, Universidade Federal do Amazonas, Manaus, 2016.

BRASIL. Ministério do Desenvolvimento Agrário. Agricultura familiar e desenvolvimento agrário. 2016. Disponível em: < http://www.mda.gov.br/sitemda/ noticias/extens\%C3\%A3o-rural-completa-50-anos-no-amazonas $\geq$. Acesso em: 15 maio 2017.

BRAGA, Rhalf Magalhães . O espaço geográfico: um esforço de definição. GEOUSP - Espaço e Tempo, São Paulo, n. 22, p. 65-72, 2007. Disponível em: $<$ http://www.geografia.fflch.usp.br/publicacoes/Geousp/Geousp22/Artigo_ Rhalf.pdf>. Acesso em: 4 nov. 2017.

CABRAL, Josélia. Olhares sobre a realidade do ribeirinho: uma contribuição ao tema. Presença - Revista de Educação, Cultura e Meio Ambiente, Porto Velho RO, v. 209, n. 24, maio. Disponível em: <http://www.revistapresenca.unir.br/ artigos_presenca/24joseliafontenele_olharessobrearealidadedoribeirinho.pdf $>$. Acesso em: dez. 2013.

DIEGUES, Antonio - MOREIRA, André. Espaços e recursos naturais de uso comum. In: NODA, Sandra et al. (Org.).Utilização e apropriação das terras pela agricultura familiar amazonense de Várzeas. São Paulo: NUPAUB/USP, 2001. 
DENEVAN, William. The aboriginal population of Amazonia. In: DENEVAN, W. (Ed.) The native population of the Americas. Madison, Wisconsin: The University of Wisconsin Press, 1976. p. 205-235.

GONÇALVES JÚNIOR, E. S. Terraços fluviais quaternários das regiões de Careiro-da-Várzea, Manaquiri, Careiro-Castanho e Autazes, Amazônia Central. 2013. Dissertação (Mestrado) - Programa de Pós-Graduação em Geociências, Universidade Federal do Amazonas, 2013.

GONÇALVES, Carlos Walter Porto. Amazônia, Amazônias. 2 ed. São Paulo: Contexto, 2005.

LATHRAP, Donald W. O Alto Amazonas. Tradução de Maria Adelaide Garcia. Lisboa: Verbo, 1975. (História Mundi, 40).

LOUZADA, Camila. As grandes obras para reabertura da BR-319 e seus impactos nas localidades ribeirinhas do Rio Solimões: Bela Vista e Manaquiri, no Amazonas. 2014. Dissertação (Mestrado em Geografia) - Programa de Pós-Graduação em Geografia, Universidade Federal do Amazonas, 2014. Disponível em: <http:// tede.ufam.edu.br/bitstream/tede/3983/2/Disserta\%C3\%A7\%C3\%A3o\%20-\%20 Camila\%20de\%20Oliveira\%20Louzada.pdf>. Acesso em: 12 jan. 2017.

MEGGERS, Betty. Amazônia: a ilusão de um paraíso. Tradução de Maria Yedda Linhares. Rio de Janeiro: Civilização Brasileira, 1977.

MENDES, Judas Tadeu Grassi; PADILHA JUNIOR, João Batista. Agronegócio: uma abordagem econômica. São Paulo: Prentice Hall, 2007.

OLIVEIRA, Leandro R. Campo e cidade na Amazônia: tendência de urbanização e o desenvolvimento. Revista Educação Popular na Amazônia - Educandos e Educadores, Escolas de Formação Sindical Amazônia e Chico Mendes, 2002.

PACHECO, Jesuete Brandão; BRANDÃO, José Carlos Martins; CARVALHO, José Alberto Lima de. Geomorfologia fluvial do Rio Solimóes/Amazonas: estratégias do povo varzeano do sudoeste do Careiro da Várzea. Revista Geonorte, edição especial, Manaus, v.2, n.4, p.542-554. 2012.

PACHECO, Jesuete Brandão; BRANDÃO, José Carlos Martins; CARVALHO, José Alberto Lima de. As estratégias das famílias amazônicas e as Terras Caídas do Curari (Amazonas-Brasil), entre as décadas de 1970-1990. In: XIV COLÓQUIO IBÉRICO DE GEOGRAFIA, 14. Actas... Braga (Portugal), 2014.

PACHECO, Jesuete Brandão. Uso e ocupação da terra e a sustentabilidade ambiental da dinâmica fluvial das microbacias hidrográficas Zé Açu e Tracajá na Amazônia Ocidental. 2013. 269 f. Tese (Doutorado) - Pós-Graduação do Centro de Desenvolvimento Sustentável, Universidade de Brasília, Brasília (DF), 2013.

PEREIRA, Raimundo Emerson Dourado. Pela margem: ribeirinhos e transformações sociais na Amazônia. 2016. 180 f. Tese (Doutorado) - Programa de Estudos da Pós-graduação em Ciências Sociais, Pontifícia Universidade Católica de São Paulo. Disponível em: < https://sapientia.pucsp.br/handle/ handle/19304>. Acesso em: 2 jul. 2017.

PINTO, Mônica Cortêz. Correlações entre as dinâmicas geomorfológicas e pecuárias na margem esquerda do Rio Madeira, município de Autazes (AM). 
2016. Dissertação (Mestrado) - Programa de Pós-Graduação em Geociências, Universidade Federal do Amazonas, Manaus, 2016. Disponível em: <http:// ppggeo.ufam.edu.br/docentes-e-discentes/corpo-discente/14-ppggeo/ dissertacoes/dissertacoes/248-defesas-2016>. Acesso em: 21 mar. 2017.

POSEY, Darrell. A. Os Kayapó e a natureza. Ciência Hoje, Rio de Janeiro, v. 2, n. 12, p. 34-41, 1980.

REGO, Nelson; CASTROGIOVANNI, A. Carlos; KAERCHER, André N. Geografia, práticas pedagógicas para o ensino médio. São Paulo: Artmed, 2007.

ROOSEVELT, A. C., M. et al. Paleoindian cave dwellers in the Amazon: the peopling of the Americas. Science, n. 272 p. 373-384, 1996. Disponível em: <https://www.researchgate.net/publication/235237012_Paleoindian_Cave Dwellers_in_the_Amazon_The_Peopling_of_the_Americas $>$. Acesso em: 1 nov. 2017.

SANTOS, Milton. Metamorfose do espaço habitado. São Paulo: Hucitec, 1988. 2006. . A natureza do espaço. São Paulo: Editora da Universidade de São Paulo,

SIOLI, Harald. Amazônia - Fundamentos da ecologia da maior região de florestas tropicais. Petrópolis: Vozes, 1990.

- O Amazonas e seus principais afluentes: tipos de rios, hidrografia e morfologia dos cursos dos rios. [Traduzido por ALR] In: SIOLI, Harald (Ed.). The Amazon - Limnology and landscape ecology of a nighty tropical river and ist basin. Dordrecht: Springer Netherlands, 1984.

SILVA, J. ; SOUZA FILHO, T. A. de. O viver ribeirinho. In: Nos banzeiros do rio: ação interdisciplinar em busca da sustentabilidade em comunidades ribeirinhas da Amazônia. Porto Velho/RO: EDUFRO, 2002.

STERNBERG, H. O. A água e o homem na Várzea do Careiro. 2 ed. Belém: MPEG, 1998.

SORRE, Max. El hombre en la tierra. Barcelona: Labor, 1967.

TOCANTINS, Leandro. O rio comanda a vida: uma interpretação da Amazônia. 4. ed. Rio de Janeiro, 1964.

TUAN, Yi-Fu. Topofilia: um estudo da percepção, atitudes e valores do meio ambiente. São Paulo: DIFEL/Difusão Europeia do Livro, 2012.

VIANNA, Lucila. De invisíveis a protagonistas: populações tradicionais e unidades de conservação. Rio de Janeiro: Annablume, 2008.

ZAMBRA, Elisandra Marisa; TRIGUEIRO, Francisco Mirialdo Chaves; PEREIRA, Raquel da Silva. Produção e comercialização de produtos da agricultura familiar sob a ótica do desenvolvimento sustentável: um estudo no Mercado do Porto em Cuiabá-MT. In: ENCONTRO INTERNACIONAL SOBRE GESTÃO EMPRESARIAL E MEIO AMBIENTE, 16. Anais... São Paulo, 2014. Disponível em: <http://www.engema.org.br/XVIENGEMA/56.pdf>. Acesso em: 29 mar. 2017. 
Camila de Oliveira Louzada - Graduação em Geografia pela Universidade Federal do Amazonas. Mestrado em Geografia pela mesma universidade. Doutoranda em Geografia pela Universidade Federal do Ceará. Atualmente é professora monitora da Escola do Meio Ambiente, na Universidade Estadual do Amazonas. ORCID: https://orcid.org/0000-0001-6780-8459

Jesuéte Pacheco Brandão - Graduação em Geografia pela Universidade Federal do Amazonas. Mestrado em Geografia pela mesma universidade. Doutora em Desenvolvimento Sustentável pela Universidade Nacional de Brasília. Atualmente é professora do Departamento de Geografia da Universidade Federal do Amazonas. ORCID: https://orcid.org/0000-0002-9570-0514

Elizabeth da Conceição Santos - Graduação em Matemática. Mestrado em Ensino de Ciências e Matemática pela Universidade Estadual de Campinas. Doutora em Educação pela Universidade Federal do Mato Grosso (UFMT) e pós-doutora em Geografia pela Universidade Federal do Ceará. Atualmente é professora e coordenadora da Escola do Meio Ambiente na Universidade do Estado do Amazonas. ORCID: https://orcid. org/0000-0001-8247-336X

\section{Contribuições dos autores}

As autoras trabalharam conjuntamente com contribuições científicas e intelectuais ao estudo. A primeira autora realizou a coleta, a tabulação, a interpretação de dados e a preparação inicial do manuscrito, assim como sua revisão final. A segunda autora e a terceira colaboraram com a discussão dos resultados, oferecendo substanciais contribuições de referencial e de interpretação dos dados coletados, assim como a organização do manuscrito.

Recebido para publicação em 10 de dezembro de 2017

Aceito para publicação em 28 de janeiro de 2018 